\section{BHIVA guidelines}

Department of GU

Medicine and

Communicable

Diseases, Imperial

College School of

Medicine, St Mary's

Hospital, Norfolk

Place, London W2 1PG

G P Taylor

\section{Department of}

Paediatrics, Imperial

College School of

Medicine, St Mary's

Hospital, Norfolk

Place, London W2 1PG

E G H Lyall

G Tudor-Williams

\section{Department of}

Sexually Transmitted

Diseases, University

College London

Medical School, The

Mortimer Market

Centre, Mortimer

Market, London

WC1E 6AU

D Mercey

\section{Department of}

Obstetrics and

Gynaecology, Chelsea

and Westminster

Hospital, Fulham

Road, London

SW10 9NH

R Smith

Women's Health

Counselling Service, St

George's Healthcare

NHS Trust, St

George's Hospital,

Blackshaw Road,

London SW17 0QT

$\mathrm{T}$ Chester

Department of

Epidemiology and

Public Health,

Institute of Child

Health, University of

London, 30 Guildford

Street, London

WC1N 1EH

M-L Newell

Correspondence to:

Dr Graham P Taylor.

Accepted for publication

18 January 1999

\title{
British HIV Association guidelines for prescribing antiretroviral therapy in pregnancy (1998)
}

Graham P Taylor, E G Hermione Lyall, Danielle Mercey, Richard Smith, Tracey Chester, Marie-Louise Newell, Gareth Tudor-Williams

The aim of antiretroviral therapy in pregnancy is to deliver a healthy uninfected child to a healthy mother, without prejudicing the future treatment opportunities of the mother. The use of zidovudine monotherapy rapidly became standard practice once it had been shown to reduce by $67 \%$ mother to child transmission in women with CD4+ lymphocyte counts above $200 \times 10^{6} / 1$. High rates of transmission are seen when maternal disease is advanced (high viral load, low CD4+ lymphocyte counts) despite zidovudine. In these women highly active antiretroviral therapy gives the best prospect for prolonged health and it is anticipated that reducing plasma viral load below the limits of detection will further reduce transmission rates. However, safety data for antiretroviral therapy in pregnancy are limited and each additional treatment exposes a significant proportion of uninfected infants to potential long term hazards. Where maternal therapy is not indicated and the sole objective of treatment is to reduce mother to child transmission, recent data suggest that short course zidovudine (especially in conjunction with prelabour caesarean section) is a reasonable option. This may minimise the emergence of viruses with reduced sensitivity to zidovudine and preserve maternal options for later therapy.

(Sex Transm Inf 1999;75:90-97)

Keywords: guidelines; antiretroviral therapy; pregnancy; zidovudine; BHIVA

\section{Introduction}

In inner London as many as one in 200 pregnant women are infected with $\mathrm{HIV}-1 .{ }^{1}$ Mother to child transmission of HIV can be reduced from $25 \%$ to less than $2 \%$ by avoidance of breast feeding, appropriate management of the delivery, and by antiretroviral therapy. Therapy in non-pregnant adults (and children) is advancing rapidly with 14 compounds accessible in the United Kingdom. The current consensus is that therapy should be initiated with three compounds, usually two nucleoside analogues (NARTI) and a protease inhibitor (PI) or non-nucleoside reverse transcriptase inhibitor (NNRTI), to delay treatment failure. ${ }^{2}{ }^{3}$ Treatment of a non-pregnant woman with monotherapy would be deemed poor medical practice. Conversely, the most significant advance in the prevention of mother to child transmission has been zidovudine monotherapy which reduces the number of infected infants by $67 \%,{ }^{4}$ and remains the only treatment for which substantial safety data in pregnancy exist. ${ }^{5}$

In this paper we summarise the available data and attempt to balance the therapeutic needs of the mother and the possibility of reducing mother to child transmission with the considerations for the fetus and infant. Antenatal screening, breast feeding, mode of delivery, prolonged rupture of membranes, and vaginal cleansing are not discussed.

\section{Safety data}

None of the currently available antiretroviral agents has been shown to be safe during the first trimester of pregnancy in humans, and women of child bearing age prescribed these drugs should be clearly informed of this lack of safety data. The FDA classification and animal carcinogenicity and teratogenicity studies are summarised in table 1 .

\section{ZIDOVUDINE}

Pharmacokinetic studies indicate that no dose adjustment of zidovudine is required in pregnancy, that zidovudine crosses the placenta reaching therapeutic levels in the cord blood and is present in breast milk. ${ }^{6}$ In the AIDS Clinical Trials Group (ACTG) Protocol 076 study zidovudine was well tolerated by mothers and infants. ${ }^{4}$ Although children exposed to zidovudine were more likely to be anaemic than those on placebo the anaemia was mild and resolved without treatment following completion of the regimen. Bone marrow toxicity did not cause problems in the mothers. A similar lack of toxicity was found in the PACTG 185 study comparing zidovudine plus intravenous HIV specific IgG with zidovudine and human immunoglobulin even though more mothers had advanced HIV disease than in the ACTG 076 study. ${ }^{7}$ No maternal or infant toxicity has been seen with short duration zidovudine monotherapy in HIV infected women in west Africa $^{8}$ or in Thailand. ${ }^{9}$ To date no long term sequelae have been found in zidovudine exposed children from the ACTG 076 study who are being followed to age 21 years, in the PACTG 219 study. ${ }^{10}$ Outside these studies no increase in congenital abnormalities has been observed in a further 300 children exposed to zidovudine during pregnancy including 89 children exposed during the first trimester. ${ }^{5}$

In carcinogenicity studies mice exposed to high dose zidovudine in utero and for a prolonged postnatal period (but not if only exposed in utero) developed vaginal tumours 
in late adult life. ${ }^{11}$ In mice, but not in humans, zidovudine is predominantly excreted unmetabolised in urine. Reflux of urine into the vagina is common in mice and the tumours may be a consequence of chronic chemical irritation. An increased incidence of solid tissue tumours has also been reported in adult CD-1 mice exposed to high dose zidovudine in utero. ${ }^{12}$ Whether this is relevant for humans will be determined by long term studies and by linking registers of perinatal antiretroviral exposure to death and cancer registries.

\section{LAMIVUDINE}

Lamivudine is well tolerated in non-pregnant adults and children and has been extensively used with zidovudine in dual and triple therapy. In a South African study zidovudine (250 mg twice daily) was compared with lamivudine (300 mg twice daily) and with the two combined (zidovudine $250 \mathrm{mg}$ twice daily, lamivudine $150 \mathrm{mg}$ twice daily). ${ }^{13}$ Late pregnancy (therapy was initiated at week 38) did not significantly alter the handling of lamivudine, alone or in combination with zidovudine. In the neonates, clearance was slower than in older children and the recommended dose has been halved to $4 \mathrm{mg} / \mathrm{kg} /$ day. No toxicity was reported in the 20 mothers and children. Lamivudine crossed the placenta efficiently and was excreted in breast milk. In a retrospective study in Houston, 16 mothers were prescribed zidovudine with lamivudine during pregnancy from a mean of 18 (SD 7.8) weeks' gestation with no side effects. Of the seven infants born at the time of review one developed anaemia, but did not require transfusion. ${ }^{14}$

DIDANOSINE

Didanosine in pregnancy is under study in the ACTG 249 protocol which has included a pharmacokinetics study in 12 women of 26-36 weeks' gestation. Fifty per cent of didanosine excretion is by the kidneys and with the increased glomerular filtration rate and total body water of pregnancy the clearance of didanosine was significantly greater during pregnancy than 6 weeks post partum; however, no dose adjustment was recommended. ${ }^{15}$ As predicted from animal studies, the placental transfer of didanosine is low, approximately $30 \%$. The use of zidovudine with didanosine was encouraged and the combination was well tolerated by the mothers and infants. ${ }^{16}$ Didanosine buffer commonly causes nausea, bloating, and diarrhoea. Peripheral neuropathy is reported and there is a small risk of pancreatitis particularly in patients with more advanced HIV disease. Didanosine should not be prescribed to patients with a history of, or other risk factors for, pancreatitis. Damage to other exocrine glands can result in a sicca syndrome.

OTHER NUCLEOSIDE REVERSE TRANSCRIPTASE INHIBITORS

Studies of stavudine with lamivudine and abacavir (1592U89) with lamivudine and zidovudine are under way in pregnant women but there have been no studies of zalcitabine or stavudine monotherapy. Pharmacokinetic data from monkeys indicate that less placental transfer occurs with didanosine and zalcitabine (30\%-50\% of maternal blood levels) than with stavudine $(76 \%)$. Zalcitabine and stavudine are frequently associated with peripheral neuropathy. Abacavir is available through an expanded access programme in the United Kingdom. An occasionally fatal hypersensitivity reaction has been reported.

\section{Non-nucleoside reverse transcription inhibitors \\ NEVIRAPINE}

Nevirapine is the only NNRTI for which there are published pharmacokinetic data in preg-

Table 1 Summary of safety data for licensed antiretroviral therapy

\begin{tabular}{|c|c|c|c|c|}
\hline & $\begin{array}{l}\text { FDA } \\
\text { pregnancy } \\
\text { category }\end{array}$ & $\begin{array}{l}\text { Placental passage } \\
\text { [newborn:maternal drug ratio] }\end{array}$ & $\begin{array}{l}\text { Long term animal carcinogenicity } \\
\text { studies }\end{array}$ & Rodent teratogenicity \\
\hline Zidovudine & $\mathrm{C}$ & Yes [0.85] (human) & Positive (rodent vaginal tumours) & Positive (near lethal dose) \\
\hline Zalcitabine & $\mathrm{C}$ & Yes [0.3-0.5] (rhesus) & $\begin{array}{l}\text { Positive (rodent thymic } \\
\text { lymphomas) }\end{array}$ & $\begin{array}{l}\text { Positive (hydrocephalus at } \\
\text { high dose) }\end{array}$ \\
\hline Didanosine & B & Yes [0.5] (human) & $\begin{array}{l}\text { Negative (no tumours, lifetime } \\
\text { rodent study) }\end{array}$ & Negative \\
\hline Stavudine & $\mathrm{C}$ & Yes [0.76] & Not completed & $\begin{array}{l}\text { Negative (decreased } \\
\text { sternum calcium at high } \\
\text { dose) }\end{array}$ \\
\hline Lamivudine & $\mathrm{C}$ & Yes $[\sim 1.0]$ & $\begin{array}{l}\text { Negative (no tumours, lifetime } \\
\text { rodent study) }\end{array}$ & Negative \\
\hline Saquinavir & B & Unknown & Not completed & Negative \\
\hline Indinavir & $\mathrm{C}$ & Yes (rats but low in rabbits) & Not completed & Negative (extra ribs in rats) \\
\hline Ritonavir & $\mathrm{B}$ & Yes (rats) & Not completed & $\begin{array}{l}\text { Negative (cryptorchidism in } \\
\text { rats) }\end{array}$ \\
\hline Nelfinavir & B & Unknown & Not completed & Negative \\
\hline Nevirapine & $\mathrm{C}$ & Yes [ 1.0] (human) & Not completed & Negative \\
\hline Delavirdine & $\mathrm{C}$ & Yes (rats) & Not completed & Ventricular septal defect \\
\hline
\end{tabular}

$\mathrm{A}=$ adequate well controlled studies of pregnant women fail to demonstrate a risk to the fetus during the first trimester of pregnancy and there is no evidence of risk during later trimesters.

$\mathrm{B}=$ animal reproduction studies fail to demonstrate a risk to the fetus and adequate well controlled studies of pregnant women have not been conducted.

$\mathrm{C}=$ safety in human pregnancy has not been determined, animal studies are either positive for fetal risk or have not been conducted, and the drug should not be used unless the potential benefit outweighs the potential risk to the fetus.

$\mathrm{D}=$ positive evidence of human fetal risk based on adverse reaction data from investigational or marketing experiences, but the potential benefits from the use of the drug in pregnant women may be acceptable despite its potential risks.

$\mathrm{X}=$ studies in animals or reports of adverse reations have indicated that the risk associated with the use of the drug for pregnant women clearly outweighs any possible benefit. 
nancy. Nevirapine's long half life (45 hours following a single dose in adults) is even longer in pregnant women (66 hours) and nevirapine crosses the placenta efficiently. A single dose of nevirapine administered to eight mothers during labour with an additional single dose given to the infant at 48-72 hours resulted in blood levels in the neonate which remained above the IC $_{90}$ for 7 days. ${ }^{17}$ No adverse events were reported, but numbers are small and there are no data from use earlier in pregnancy. A severe skin rash is the most commonly recognised side effect of nevirapine and liver function tests may become abnormal. In a retrospective study in London no side effects were seen in nine children exposed to nevirapine during the second and third trimesters of pregnancy. ${ }^{18}$ An international multicentre study, including European centres, is under way to evaluate whether the addition of nevirapine to existing therapy will further reduce the risk of mother to child transmission (PACTG 316).

\section{DELAVIRDINE}

Delavirdine is generally well tolerated with rash and abnormal liver function tests the most common side effects. Thrice daily dosing and high tablet count (12/day) are disadvantages. It is licensed in the United States and available through an expanded access programme in the United Kingdom. There are no data from pregnant women.

\section{EFAVIRENZ}

Efavirenz (DMP266) is available through an expanded access programme but women must not be pregnant and must agree to use barrier and non-barrier methods of contraception. Although rodent studies had been normal teratogenicity was noted in cynomolgus monkeys, with severe defects (anencephaly and microphthalmia) in 3/13 fetuses (Dupont, communication to investigators, 1998).

\section{PROTEASE INHIBITORS}

Protease inhibitors (PIs) have become an integral part of combination therapy in adults and children. Recruitment to studies of pregnant women in the United States were temporarily halted following the observation of increased premature labour in women receiving combination therapy which included PIs. ${ }^{19}$ These studies have resumed with more stringent entry criteria which exclude women with advanced HIV disease or a history of preterm deliveries.

\section{Saquinavir}

Saquinavir has been the best tolerated of the PIs but only $4 \%$ of the dose of hard gel capsules is bioavailable in healthy volunteers. Bioavailability has improved with the new soft gel formulation but the recommended dose has also been increased from $600 \mathrm{mg}$ to $1200 \mathrm{mg}$ three times daily (18 capsules per day). A Thailand/UK pharmacokinetics study of zidovudine, lamivudine, and soft gel saquinavir is under way.

\section{Ritonavir}

Ritonavir is more poorly tolerated, with perioral paraesthesia, nausea, vomiting, and diar- rhoea, and as patients often require long term antiemetic and antidiarrhoeal therapy ritonavir may not be preferred in pregnancy. Recruitment to an ACTG pharmacokinetics study of ritonavir in pregnancy has started.

\section{Indinavir}

Indinavir is associated with new onset diabetes and a worsening of established diabetes and may therefore compound gestational hyperglycaemia. Hypercholesterolaemia and hypertriglyceridaemia occur within weeks of therapy, while changes in body fat distribution, particularly tender breast enlargement, may cause distress in some women. Elevated liver enzymes are common and hyperbilirubinaemia although conjugated may compound neonatal jaundice. Haemolytic anaemia has also been reported while crystallisation of indinavir in the renal tract precipitates renal stones which could damage the immature renal system. In the Swiss cohort one child exposed to indinavir, zidovudine, and lamivudine from the first trimester was born with biliary atresia, ${ }^{19}$ a rare congenital malformation. A combination of indinavir, lamivudine, and zidovudine in pregnancy is being studied.

\section{Nelfinavir}

Nelfinavir appears to be better tolerated than ritonavir and indinavir but diarrhoea is a common and troublesome side effect. The ACTG 353 study will determine the pharmacokinetics of nelfinavir in pregnant women.

\section{Antiretroviral therapy to prevent HIV mother to child transmission}

Only zidovudine has been shown to prevent mother to child transmission in controlled studies. The ACTG 076 study was stopped following an interim analysis of the first 363 evaluable infants which showed a $67 \%$ reduction in transmission from $25.5 \%$ to $8.3 \%{ }^{4}$ The zidovudine regimen is detailed in table 2 . The majority of women were in good health, only $5 \%$ had received prior zidovudine therapy and all had a CD4+ lymphocyte count greater than $200 \times 10^{6} / 1$. The median CD4+ lymphocyte count at baseline was $550 \times 10^{6} / 1$ and the median plasma viral load (measured by RTPCR and bDNA assays) was 5700 HIV RNA copies per $\mathrm{ml}$. In the final analysis of all 402 evaluable infants transmission rates were $22.6 \%$ in the placebo arm and $7.6 \%$ in the zidovudine arm. ${ }^{20}$ Following the publication of these results the use of zidovudine monotherapy by pregnant women aware of their HIV infection has risen from $22 \%$ to $89 \%,{ }^{21-24}$ with transmission rates falling from $19 \%$ to $8 \%$ and from $14 \%$ to $5 \%$ in New York/Puerto Rico ${ }^{21}$ and France ${ }^{22}$ respectively. Evidence from the PACTG 185, study in which the women had a median baseline CD4+ lymphocyte count of $306 \times 10^{6} / 1$, a median viral load of $18500 \mathrm{HIV}$ RNA copies per ml plasma, and $21 \%$ had previously taken zidovudine for extended periods suggests that zidovudine is also effective in women with more advanced disease. ${ }^{7}$ This study of passive immunotherapy was terminated early because the overall transmission 
Table 2 Recommended doses of antiretroviral therapy during pregnancy

\begin{tabular}{|c|c|c|}
\hline & $A C T G 076^{4}$ & London group \\
\hline \multicolumn{3}{|l|}{ Zidovudine } \\
\hline \multicolumn{3}{|l|}{ Maternal dose } \\
\hline $\begin{array}{l}\text { during } 2 \mathrm{nd} \text { and } 3 \mathrm{rd} \\
\text { trimesters }\end{array}$ & $100 \mathrm{mg}$ five times/day & $250 \mathrm{mg}$ twice daily \\
\hline \multicolumn{3}{|l|}{ Intrapartum } \\
\hline Loading dose & $2 \mathrm{mg} / \mathrm{kg}$ IVI over 1 hour & $2 \mathrm{mg} / \mathrm{kg}$ IVI over 1 hour \\
\hline Maintenance dose $†$ & $1 \mathrm{mg} / \mathrm{kg}$ IVI hourly & $1 \mathrm{mg} / \mathrm{kg}$ IVI hourly \\
\hline Neonatal dose & $\begin{array}{l}2 \mathrm{mg} / \mathrm{kg} \text { four times daily } \\
\text { for } 6 \text { weeks }\end{array}$ & $\begin{array}{l}2 \mathrm{mg} / \mathrm{kg} \text { four times daily for } 3 \\
\text { weeks }\end{array}$ \\
\hline Lamivudine & & Johnson $e t a l^{13}$ \\
\hline Prepartum weeks 38-40 & & $150 \mathrm{mg}$ twice daily \\
\hline At onset of labour & & $150 \mathrm{mg}$ immediately \\
\hline Neonatal & & $2 \mathrm{mg} / \mathrm{kg}$ twice daily \\
\hline Didanosine & & ACTG $249^{1516}$ \\
\hline \multicolumn{3}{|l|}{ Prepartum } \\
\hline 3rd trimester & & $\begin{array}{l}200 \mathrm{mg} \text { twice daily }>60 \mathrm{~kg} \\
125 \mathrm{mg} \text { twice daily }<60 \mathrm{~kg}\end{array}$ \\
\hline \multicolumn{3}{|l|}{ Intrapartum } \\
\hline Loading dose & & $1 \mathrm{mg} / \mathrm{kg}$ IVI over 1 hour \\
\hline Maintenance dose & & $0.25 \mathrm{mg} / \mathrm{kg} / \mathrm{h}$ IVI \\
\hline Nevirapine & & ACTG $250^{17}$ and 316 \\
\hline At onset of labour & & $200 \mathrm{mg}$ immediately \\
\hline Neonatal & & $\begin{array}{l}2 \mathrm{mg} / \mathrm{kg} \text { immediately at } 48-72 \\
\text { hours }\end{array}$ \\
\hline \multirow{2}{*}{$\begin{array}{l}\text { During 2nd and 3rd } \\
\text { trimesters } \ddagger\end{array}$} & & $200 \mathrm{mg}$ once daily for 2 weeks \\
\hline & & $200 \mathrm{mg}$ twice daily thereafter \\
\hline
\end{tabular}

${ }^{\star}$ Start as early as possible in established labour and at least 1 hour before elective caesarean section.

tContinue until the cord clamped.

¥This dose regimen has not yet been confirmed in pregnancy by pharmacokinetic studies.

rate was only $4.8 \%$ and a much larger study would be necessary to demonstrate any benefit of anti-HIV IgG. It is not possible to comment on the efficacy of lamivudine, didanosine, or nevirapine in preventing mother to child transmission from the aforementioned studies.

Although short duration improvement was seen with zidovudine monotherapy in patients with advanced AIDS $^{25}$ zidovudine alone does not prolong survival in asymptomatic subjects. ${ }^{26}$ Viral load is reduced by approximately $0.5 \log _{10}$ RNA copies per $\mathrm{ml}$ following which HIV-1 quasispecies with mutations which confer reduced sensitivity to zidovudine are selected and viral load returns to baseline after approximately 6 months of therapy. In the ACTG 076 study the median viral load reduction from baseline at the time of delivery was only $0.24 \log _{10}$ copies per $\mathrm{ml}$ but zidovudine was effective at all levels of viral load and it is unlikely that viral load reduction alone is responsible. Similar benefits of zidovudine have been noted with prophylaxis following occupational exposure; transmission is reduced from $0.3 \%$ to $0.1 \%{ }^{27}$ It is not known whether other therapies would have this prophylactic effect.

Some light on the contribution of the prepartum, intrapartum, and postpartum components of the 076 regimen has been shed by two recent publications. In an observational study from New York State transmission rates were $28.8 \%$ in mother-infant pairs who did not receive zidovudine, $5.2 \%$ in those who started zidovudine antepartum, and $9.2 \%$ among 87 infants where zidovudine was only commenced during delivery or the neonatal period. Starting zidovudine more than 48 hours after delivery did not offer any protection. ${ }^{28}$ In Thailand, zidovudine $300 \mathrm{mg}$ twice daily from the 36th week of gestation and every 3 hours by mouth during labour has been compared with pla- cebo. All women were provided with formula feeds and advised not to breast feed but there was no neonatal component. There were $17 / 193(9.2 \%)$ transmissions to the children exposed to zidovudine compared with $35 / 198$ $(18.6 \%)$ in the placebo arm, a $51 \%$ reduction. The median CD4+ lymphocyte count in the mothers at baseline was 428 and 410 respectively. ${ }^{9}$ The smaller effect found in Thailand (compared with the ACTG 076 study) may have been due to the omission of the neonatal component, the deferred start of prepartum component, differences between the cohort, or obstetric factors. These data suggest that zidovudine should be offered to all mothers and their infants however late in pregnancy they present.

\section{Maternal viraemia and mother to child transmission}

Many maternal factors have been associated with an increased risk of mother to child transmission including more advanced disease, lower CD4 counts, and higher viral loads, all of which are closely related. A meta-analysis of nine studies of transmission based on 1115 mother-infant pairs describes the relation between viral load and transmission. ${ }^{29}$ In the absence of zidovudine viral loads $\geqslant 10000$ copies per $\mathrm{ml}$ were associated with $37 \%$ transmission loads of $1000<9999$ with $15 \%$. While zidovudine was associated with a $50 \%$ reduction in transmission both above and below 10000 copies per $\mathrm{ml}$, the scope for further improvement especially in those mothers with higher viral loads is clear. In Europe, Mayaux et al found that viral loads of 1000 copies per ml were associated with $2 \%$ transmission while $40 \%$ of babies are infected if the maternal viral load is $>100000$ copies per ml. ${ }^{30}$ Although viral load is more predictive, stratification by CD4 lymphocyte count produces similar results. In the PACTG 185 study, the risk of transmission with zidovudine therapy was $3.3 \%$ if maternal CD4 lymphocyte count was $>200 \times 10^{6} / 1$ compared with $9.5 \%$ if the count was $<200 \times 10^{6} / 1{ }^{7}$ It is anticipated that regimens which reduce plasma viraemia to below 500 copies per $\mathrm{ml}$ will substantially reduce the risk of transmission. However, transmissions have occurred when plasma viraemia was undetectable (less than 1000 to less than 200 copies $/ \mathrm{ml}$ ), ${ }^{30-32}$ perhaps because viral load in genital tract secretions can differ from that in plasma. ${ }^{33} 34$ As many women with $\mathrm{HIV}$ in the United Kingdom have non-B HIV genotypes, which may give falsely low or undetectable results in viral load assays we recommend using two assays, which utilise different nucleotide sequences to bind or amplify the target.

Viral load reduction in pregnancy with lamivudine $300 \mathrm{mg}$ twice daily alone or lamivudine $150 \mathrm{mg}$ twice daily plus zidovudine $250 \mathrm{mg}$ twice daily appears to be the same as in non-pregnant adults, about $1.5 \log _{10}{ }^{35}$ In the South African study, lamivudine and/or zidovudine were given only from the 38th week of pregnancy so the duration of response was not determined. However, in a small study in Lon- 
don, where women with more advanced HIV disease (CD4 count $<200 \times 10^{6} / 1$ or viral load $>30000$ HIV RNA copies per ml plasma) were treated with zidovudine and lamivudine from the start of the second trimester, a $1.5 \log _{10}$ reduction in viral load was observed at the time of delivery, after a mean of 17.6 weeks on therapy. ${ }^{36}$ Although no transmissions occurred the $\mathrm{M} 184 \mathrm{~V}$ mutation in the RT gene which denotes reduced lamivudine sensitivity was detected in plasma from four of five mothers at or before delivery. The rapid appearance of $\mathrm{M} 184 \mathrm{~V}$ is well recognised in non-pregnant populations. $^{37}$

\section{Maternal considerations}

It has become clear from the Multicenter AIDS Cohort Study that plasma viral load is the single most useful prognostic marker in HIV-1 infected men. ${ }^{38}$ In this cohort, for people with a baseline CD4+ cell count of $<350 \times 10^{6} / 1$ the probability of progressing to an AIDS defining illness within 9 years of the baseline blood sample was $95.6 \%$ if the plasma viral load was $>30000$ copies per $\mathrm{ml}$ (as measured by bDNA testing) but about $30 \%$, if the viral load was $<3000$ copies per $\mathrm{ml}$.

Limited viral load reduction is seen with zidovudine monotherapy $\left(\sim 0.5 \log _{10}\right)$, a more sustained $1.5 \log _{10}$ reduction with two NARTIs while viral load reductions in the order of 2.5 $\log _{10}$ are routinely observed with triple combinations. The duration of response is also much longer (but may not be indefinite) and the majority of patients can anticipate a reduction in viral load to below 500 copies per $\mathrm{ml}$. Significant clinical benefit with combination NARTI therapy compared with monotherapy $^{39-41}$ and a good correlation between viral load reduction and clinical response has been demonstrated. ${ }^{42}$ However, failure to fully suppress viral replication results in viral resistance and although resistance is not the only cause of therapeutic failure cross resistance occurs between some NARTIs. ${ }^{43}$ Compared with dual therapy significant improvement in clinical outcomes with triple therapy has been reported. ${ }^{44}$ The optimal time to start therapy has not been determined but plasma viral load, CD4+ lymphocyte counts, and clinical status are used as guides. ${ }^{235}$ Similarly the optimal combination even for non-pregnant women is uncertain but published guidelines recommend initiating therapy with at least three drugs, commonly two NARTIs and a PI or NNRTI. ${ }^{2}{ }^{35}$

\section{Recommendations for the pregnant mother}

ASYMPTOMATIC MOTHERS WITH HIGH CD4

LYMPHOCYTE COUNTS AND LOW PLASMA

VIRAEMIA (FIG 1 TRACK A)

How "high" CD4+ lymphocyte count and "low" viral load are defined will vary not only between centres, in part owing to the use of different viral quantification assays, but over time as experience with antiretroviral therapy in non-pregnant subjects modifies practice. Therefore, a range rather than absolute values is suggested in figure 1. Antiretroviral therapy would not be recommended if these women were not pregnant. Rouzioux et al estimated that less than $2 \%$ of mother to child transmission occurred before the third trimester. ${ }^{46}$ Data from the International Twin Registry ${ }^{47}$ and mode of delivery studies ${ }^{48-50}$ also highlight the importance of labour in mother to child transmission. We therefore conclude that zidovudine monotherapy according to the ACTG 076 regimen (see table 2) remains a reasonable option for these women but recommend that treatment is deferred until the third trimester to reduce the likelihood of resistance developing and to reduce fetal drug exposure. Although it would appear from the Thai data that the maternal component may be started as late as gestational week 36 , there is a risk that mothers may miss therapy altogether when premature labour, which is associated with increased transmission risk, occurs. Transmission rates of $<2 \%$ achieved when zidovudine monotherapy is combined with an elective caesarean section ${ }^{48-50}$ suggest that this is a valid option although short course, combination therapy may be preferred by some mothers.

Is dual therapy justified in a pregnant woman? While there is clear evidence that dual therapy with NARTIs defers progression to AIDS and prolongs life compared with monotherapy ${ }^{39}$ triple therapy in drug naive patients is more effective than dual therapy ${ }^{44}$ and initial dual therapy may reduce the efficacy of subsequent triple therapy, even with a complete change of therapy.

WOMEN WITH ADVANCED HIV DISEASE, HIGH VIRAL LOAD, OR LOW CD4 COUNTS (FIG 1, TRACK B)

For women with relatively advanced disease we recommend triple therapy. However, the decision to treat and the choice of treatment are based on fetal and maternal considerations. With the exception of zidovudine there are few or no safety data in human pregnancies with ART and with combination therapy the fetus could be exposed to several potentially toxic agents. Table 3 illustrates how many babies are exposed to a drug to protect a baby in Europe from HIV as additional therapies are added to a regimen. On the other hand the risk of mother to child transmission increases with viral load, is inversely related to CD4 counts, and is related to maternal health and remains at least $18 \%$ if the maternal viral load is greater than 10000 copies per $\mathrm{ml}$ despite zidovudine therapy. ${ }^{33}$ Since further viral load reduction is likely to reduce transmission triple therapy may also outweigh the potential, unknown hazards for the neonate as well as being beneficial to the mother. Some mothers in this category are reluctant to expose their baby to combination antiretroviral therapy. To these women we recommend zidovudine monotherapy (track A) plus an elective caesarean section.

CONCEIVING WHILE ON TREATMENT (FIG 1, TRACK C)

This is becoming more common as antiretroviral therapy is increasingly prescribed to asymptomatic patients and as patients become more 


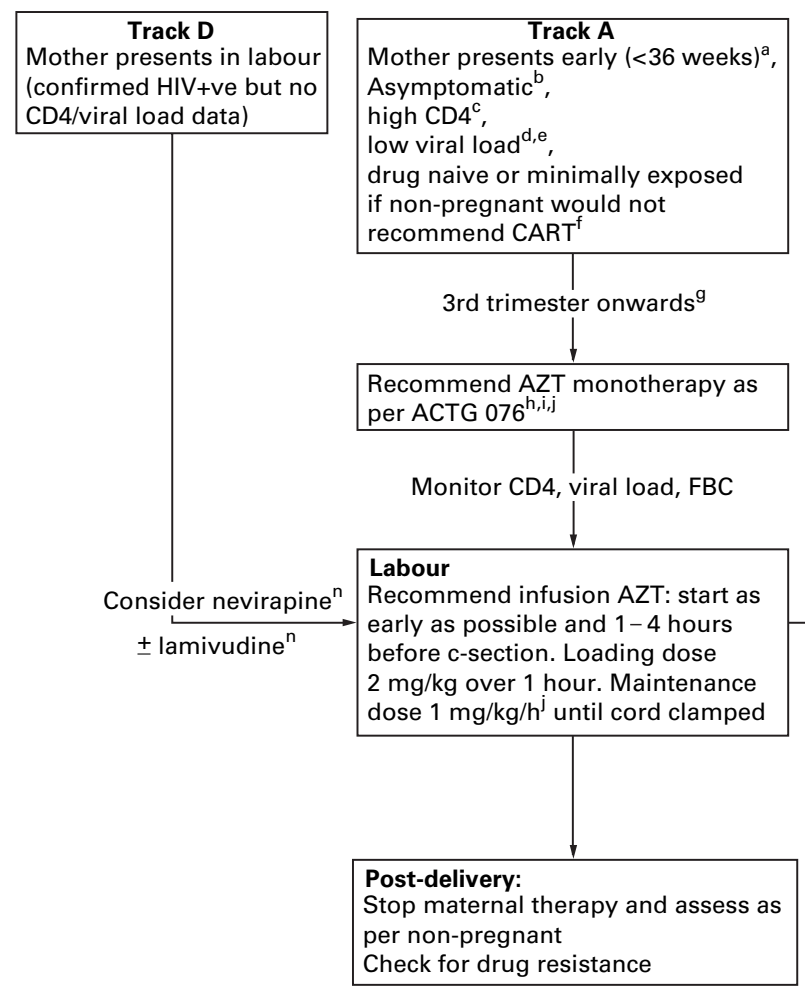

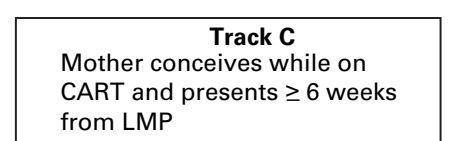

Track B
Mother symptomatic ${ }^{b}$ or

low $\mathrm{CD} 4^{\mathrm{C}}$ or

high viral load ${ }^{\text {d }}$

drug naive or minimally exposed

If non-pregnant would recommend $\mathrm{CART}^{\mathrm{f}}$

or late presentation ( $\geq 36$ weeks)

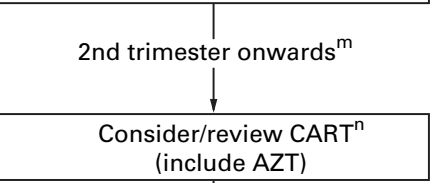
(include AZT)

Monitor CD4, FBC, LFTs viral load, and resistance

\section{Labour}

Recommend infusion AZT:

Loading dose $2 \mathrm{mg} / \mathrm{kg}$ over 1 hour

Maintenance dose $1 \mathrm{mg} / \mathrm{kg} / \mathrm{h}$

until cord clamped

Continue other NARTI or NNRTI

by mouth

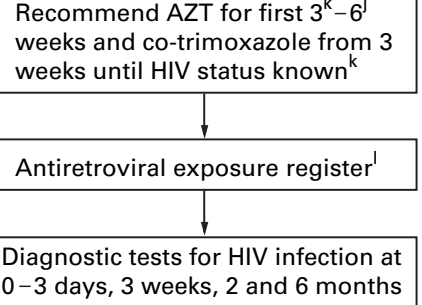

Figure 1 Algorithm for prescribing antiretroviral therapy in pregnant women. (a) Opportunity exists to establish baseline variables before initiating therapy. (b) Symptomatic disease associated with increased risk mother to child transmission. (c) Arbitrary value: $200<500 \times 10^{6} / l<200 \Rightarrow 9 \%$ transmission with zidovudine ${ }^{7}>200 \Rightarrow 3.3 \%$ transmission with zidovudine. (d) Arbitrary value: $10000<30000$ copies per ml plasma $<10000 \Rightarrow 7 \%$ transmission with zidovudine ${ }^{33}>10000 \Rightarrow 18 \%$ transmission with zidovudine. (e) Consider genotype effect. (f) See BHIVA guidelines. ${ }^{2}{ }^{3}$ (g) Early treatment with monotherapy might result in viral resistance but viral resistance unlikely when replication (viral load) low and therapy of short duration. (h) Discuss safety, anaemia, late unrecognised/unexpected adverse event. (i) Many physicians prescribe 250 mg twice daily rather than 100 mg five times daily. (j) ACTG 076 regimen. (k) Avoids combined marrow toxicity of zidovudine and co-trimoxazole (dose: co-trimoxazole 900 mg/m ${ }^{2}$ three times weekly). (1) Antiretroviral Pregnancy Registry (GlaxoWellcome Ltd, Greenford Rd, Greenford, UB6 0HE, tel: 0800413524 ; fax: 01819662338 ). (m) Balance maternal health considerations with fetal exposure to combination antiretroviral therapy (CART). (n) See discussion on CART in pregnancy.

confident about their prognosis. It is likely that by the time the newly pregnant mother realises her condition and presents to the clinic embryonic development will be complete. In these circumstances stopping treatment may be too late to prevent congenital abnormalities while subjecting the fetus to additional risk of transmission as the viral load rebounds. Therefore, continuation of the preconception regimen is recommended although the addition of, or change to, zidovudine should be considered while this remains the only agent proved to reduce mother to child transmission in humans. Some mothers planning a pregnancy may detect conception at 2-3 weeks and discontinue antiretroviral therapy until the end of the first trimester. There is no evidence to confirm or refute this practice. A transient increase in viral load above pretreatment levels has been observed in 4/5 individuals stopping treatment after $8-19$ days $^{51}$ but this may be

Table 3 Ratio of babies exposed without benefit to babies exposed with benefit for each additional antiretroviral agent added to maternal therapy

\begin{tabular}{lllll}
\hline & \multicolumn{2}{l}{ Number of babies } & \\
\cline { 2 - 4 } Therapy & At risk & Protected & $\begin{array}{l}\text { Exposed, } n \text { } \\
\text { benefit }\end{array}$ & Ratio of exposed:protected \\
\hline Zidovudine & 17 & 12 & 88 & $7.3: 1$ \\
Second agent & 5 & 3 & 97 & $32.3: 1$ \\
Third agent & 2 & 2 & 98 & $49: 1$ \\
\hline
\end{tabular}

more relevant to the risk of transmission to the neonate through breast feeding following peripartum antiretroviral therapy, than to intrauterine infection.

LATE PRESENTATIONS (FIG 1, TRACK D)

For the mother who presents too late in pregnancy to allow formal immunological and virological assessment the 076 regimen should be started with the possible addition of lamivudine and/or nevirapine (see table 2 for doses).

\section{The pretreated mother}

In the ACTG 076 study, only 1/36 mothers prescribed zidovudine had detectable genotypic resistance at the time of delivery, although in London mutations were detected 2/10 women on zidovudine monotherapy. ${ }^{36}$ In the PACTG 185 study $20 \%$ of mothers had past exposure to zidovudine but the transmission rate was still lower than in the ACTG 076 study at $4.8 \%$ while in the French cohort the transmission rate was $20 \%$ in pretreated mothers. ${ }^{22}$ It is advisable to monitor pretreated mothers for resistance mutations not only before therapy (when wild type genotype may be detected) but during therapy to detect early recurrence of mutant virus. For mothers with zidovudine resistant virus, combination therapy with an alternative NARTI should be considered. With increased prescribing of ART 
the possibility of primary infection with drug resistant HIV should be considered. ${ }^{52} 53$ Mother to child transmission of zidovudine resistant viruses has been reported. ${ }^{54}$

\section{Monitoring of exposed infants}

The outcome of all pregnancies exposed to antiretroviral therapy should be reported to the Antiretroviral Pregnancy Registry (which in Europe is managed by GlaxoWellcome Ltd, Greenford Road, Greenford, UB6 0HE, tel: 0800 413524; fax: 01819662338 ) so that any risks can be identified as quickly as possible. Infants exposed to combinations, particularly those containing protease inhibitors and other more recently licensed drugs, should be monitored for renal and hepatic toxicity in the early period after delivery until the profile of these drugs is better known. Until HIV infection has been excluded, infants should receive Pneumocystis carinii pneumonia (PCP) prophylaxis with co-trimoxazole. Although the available data suggest that zidovudine monotherapy does not delay the diagnosis of HIV infection in the infant ${ }^{55}$ this remains a theoretical risk for combination therapy. In the United Kingdom all pregnant women with HIV infection should be reported anonymously to the Royal College of Obstetricians and Gynaecologists' study which is linked to the paediatric reporting scheme run by the Royal College of Paediatrics and Child Health Surveillance Unit (Contact Ms Pat Tookey, RCOG, 27 Sussex Place, Regent's Park, London NW4 RG1, tel: 0171 829 8686). This database is linked to national death and cancer registries.

The guidelines have been prepared following widespread discussions with physicians, obstetricians, and paediatrician caring for women with HIV in London. The guidelines were debated at the British HIV Association meeting in Oxford, 1998 , following which they were modified to represent the consensus opinion in the United Kingdom.

1 Unlinked Anonymous Surveys Steering Group. Unlinked Anonymous HIV Prevalence Monitoring Programme, England and Wales. London: Department of Health, England and

2 BHIVA Guidelines Co-ordinating Committee. British HIV Association guidelines for anti-retroviral treatment of HIV seropositive individuals. Lancet 1997;349:1086-92.

3 Gazzard B, Moyle G on behalf of the BHIVA Guidelines Writing Committee. 1998 Revision to the British HIV Association guidelines for antiretroviral treatment of HIV seropositive individuals. Lancet 1998;352:314-16.

4 Connor EM, Sperling RS, Gelber R, et al. Reduction of maternal-infant transmission of human immunodeficiency virus type 1 with zidovudine treatment. $N$ Engl $\mathcal{F} M e d$ 1994;331:1173-80.

5 Anti-retroviral Pregnancy Registry for didanosine, indinavir, lamivudine, saquinavir, stavudine, zalcitabine, zidovudine Interim Report 1 January 1989 zalcitaine, zidovudine. 1997. A collaborative project managed by Bristol Myers Squibb Co, Glaxo Wellcome, Hoffman-La Roche, Inc, and Merck \& Co Inc, Research Triangle Park, NC 1997.

6 O'Sullivan MJ, Boyer PJ, Scott GB, et al. The pharmacokinetics and safety of zidovudine in the third trimester of pregnancy for women infected with human immunodeficiency virus and their infants: phase I acquired immunodeficiency syndrome clinical trials group study (protocol 082). Zidovudine Collaborative Working Group. $A m$ Obstet Gynecol 1993;168:1510-6.

7 Paediatric AIDS Clinical Trials Group Protocol 185 Executive Summary. National Institute of Child Health and Human Development, National Institutes of Health, Bethesda, MD; 1997 March 25; presented at a conference on global strategies for the prevention of HIV transmission from mothers to infants; Washington, DC, September 3-6 1997.

8 Dabis, F, Méda N, Msellati P, et al. Zidovudine to decrease mother-to-child transmission of HIV-1: A Phase II study in West Africa, 1995-1996 (ANRS 049A). Abstract TuC 444 XIth International Conference on AIDS; Vancouver, 7-12 July 1996.
9 Vuthipongse P, Bhadrakom C, Chaisilwattana P, et al. Administration of zidovudine during late pregnancy and delivery to prevent perinatal HIV transmission-Thailand, 1996-1998. MMWR 1998;47:151-4

10 Sperling RS, Shapiro DE, McSherry GD, et al. Safety of the maternal-infant zidovudine (ZDV) regimen utilised in the AIDS Clinical Trials Group 076 Protocol. [Abstract] A conference on global strategies for the prevention of HIV transmission from mothers to infants; Washington, DC, September 3-6 1997

11 Ayers KM, Clive D, Tucker WE Jr, et al. Nonclinical toxicology studies with zidovudine: genetic toxicity tests and carcinogenicity bioassays in mice and rats. Fundam Appl Toxicol 1996;32:148-58.

12 Olivero OA, Anderson LM, Diwan BA, et al. AZT is a genotoxic transplacental carcinogen in animal models. $\mathcal{F}$ Acquir Immune Defic Syndr 1997:14:A29 [Abstract 52]

13 Moodley J, Moodley D, Pillay K, et al. Pharmacokinetics and antiretroviral activity of lamivudine alone or when co-administered with zidovudine in human immunodeficiency virus type 1-infected pregnant women and their offspring. F Infect Dis 1998;178:1327-33.

14 Eriksen N, Helfgott A, Doyle M. Combination antiretroviral therapy for the treatment of HIV infection in rest pregnant women: safety profiles in women and newborns, Opportunistic Infections; 1998 February 1-5; Chicago, IL 1998 [Abstract 235].

15 Patil SD, Livingston E, McKinney RE, et al and the ACTG 249 team. Does pregnancy affect the pharmocokinetics of didanosine (ddI) in HIV-1 infected women? Abstracts of the 5th Conference on Retroviruses and Opportunistic Infections; 1998 February 1-5; Chicago, IL, 1998 [Abstract 225].

16 Livingston E, Patil SD, Unadkat JD, et al and the ACTG 249 team. Placental transfer of didanosine (ddI) and initia evaluation of didanosine toxicity in HIV-1 infected pregnant women and their offspring. Abstracts of the 5th pregnt 1998 February 1-5; Chicago, IL, 1998 [Abstract 226].

17 Mirochnick M, Fenton T, Gagnier P, et al for the Pediatric Aids Clinical Trials Group Protocol 250 Team. Pharmacokinetics of nevirapine in human immunodeficiency virus type 1-infected pregnant women and their newborns. $f$ type 1-infected pregnant won

18 Jungmann E, Mohan D, Mercey D, et al. Outcome of HIV-1 positive pregnancies in London since the introduction of the ACTG 076 Protocol: a retrospective analysis. 4th International Congress on Drug Therapy in HIV Infection Glasgow; 1998 Nov 8-12; [P313A] In AIDS 1998; 12(suppl 4):S96.

19 Lorenzi P, Masserei V, Laubereau B, et al. Safety of combined anti-retroviral therapies with or without protease inhibitors in pregnant HIV-infer women and their offspring. Conference Supplement, 12th World AIDS Conference Geneva; 1998 June 28-July 3 [Abstract

Sperling RS, Shapiro DS, Coombs RW, et al. Maternal viral load, zidovudine treatment, and the risk of transmission of HIV-1 from mother to infant. N Engl f Med 1996;335 1621-9.

21 Cooper ER, Nugent RP, Diaz C, et al. After AIDS Clinical Trial 076: the changing pattern of zidovudine use during pregnancy, and subsequent reduction in the vertical transmission of human immunodeficiency virus in a cohort of infected women and their infants. F Infect Dis 1996;174: $1207-11$

22 Mayaux M-J, Teglas J-P, Mandelbrot L, et al. Acceptability and impact of zidovudine for prevention of mother-to-child human immunodeficiency virus-1 transmission in France. human immunodeficiency

23 Gibb DM, MacDonagh SE, Tookey PA, et al. Uptake of interventions to reduce mother-to-child transmission of HIV in the United Kingdom and Ireland. AIDS 1997;11 F53-8.

24 Lyall EGH, Stainsby C, Taylor GP, et al. Review of the uptake of interventions to prevent mother to child transmission of HIV by women aware of their HIV status. BMF 1998;316:268-70.

25 Fischl MA, Richman DD, Grieco MH, et al. The efficacy of azidothymidine (AZT) in the treatment of patients with AIDS and AIDS-related complex: a double-blind placebo controlled trial. N Engl f Med 1987; 317:192-7.

26 Concorde Coordinating Committee. MRC/ANRS ran domised double blind controlled trial of immediate and deferred zidovudine in symptom-free HIV infection. Lancet $1994 ; 343: 871-81$

27 Centers for Disease Control. Case control study of HIV seroconversion in health care workers after percutaneous exposures to HIV-infected blood: France, UK and US, Jan '88-Aug '94. MMWR 1995;44:607-60.

28 Birkhead GS, Warren BL, Charbonneau TT, et al. Evidence for intermediate rates of perinatal HIV transmission with partial 076 regimens: results of an observational study. Abstracts of the 5th Conference on Retroviruses and Opportunistic Infections; 1998 February 1-5; Chicago, IL 1998 [Abstract 244].

29 Cao Y, Krogstad P, Korber BT, et al. Maternal HIV-1 viral load and vertical transmission of infection: the Ariel Project for the prevention of HIV transmission from mother to infant. Nat Med 1997;3:549-52.

30 Mayaux MJ, Dussaix E, Isopet J, et al. Maternal virus load during pregnancy and mother to child transmission of human immunodeficiency virus type 1 : the French perina- 
tal cohort studies. SEROGEST Cohort Group. $\mathcal{F}$ Infect Dis $1997 ; 175: 172-5$

31 Thea DM, Steketee RW, Pliner V, et al. The effect of maternal viral load on the risk of perinatal transmission of HIV-1. AIDS 1997;11:437-44.

32 Rasheed S, Li Z, Xu D, et al. Presence of cell-free human immunodeficiency virus in cervicovaginal secretions is independent of viral load in the blood of human immunodeficiency virus-infected women. Am 7 Obstet Gynecol 1996;175:122-9.

33 Contopoulos-Ioannidis DG, Ioannidis JPA. Maternal cellfree viraemia in the natural history of perinatal HIV-1 transmission. F Acquir Immune Defic Syndr Hum Retrovirol transmission. F $A$.

34 O'Shea S, Newell M-L, Dunn DT, et al. Maternal viral load, CD 4 count and vertical transmission of HIV-1. F Med Virol 1998;54:113-17.

35 Coovadia HM, Moodley D, Moodley J, et al. Viral load and perinatal transmission in HIV-1 infected black South African women and their infants given lamivudine (3TC) alon or in combination with zidovudine (AZT) [NUCB 2018] A conference on global strategies for the prevention of HIV transmission from mothers to infants; 1997 September 3-6; Washington, DC [Abstract].

36 Clarke JR, Braganza R, Ait-Khaled M, et al. Rapid development of the M184V mutation in women receiving zidovudine and lamivudine during pregnancy. [Abstract 131-W9] 3rd European Conference on Experimental AIDS Research (ECEAR); 1998 Feb 28-Mar 3; Munich, 1998.

37 Schuurman R, Nijhuis M, van-Leeuwen LM, et al. Rapid changes in human immunodeficiency virus type 1 RNA changes in human immunodeficiency virus type $1 \mathrm{RNA}$ load and appearance of drug resistant virus populations in
persons treated with lamivudine (3TC). F Infect Dis persons treated with

38 Mellors JW, Munoz A, Giorgi JV, et al. Plasma viral load and CD4+ lymphocytes as prognostic markers of HIV-1 infection. Ann Intern Med 1997;126:946-54

39 Delta Coordinating Committee. Delta: a randomised double-blind controlled trial comparing combinations of zidovudine plus didanosine or zalcitabine with zidovudine alone in HIV-infected individuals. Lancet 1996;348:283 91.

40 Hammer SM, Katzenstein DA, Hughes MD, et al. A trial comparing nucleoside monotherapy with combination 200-500 per cubic millimeter. $N$ Engl f Med 1996:335: $1081-90$

41 Randomised trial of addition of lamivudine or lamivudine plus loviride to zidovudine-containing regimens for patients with HIV-1 infection: the CAESAR trial, Lancet 1997;349:1413-21.

42 Brun-Vézinet F, Boucher C, Loveday C, et al. HIV-1 viral load, phenotype, and resistance in a subset of drug-naive participants from the Delta trial. Lancet 1997;350:983-90.
43 Hirsch MS, Conway B, D'Aquila RT, et al. Antiretroviral drug resistance testing in adults with HIV infection. $\mathscr{f} A M A$ 1998;279:1984-91

44 Hammer SM, Squires KE, Hughes MD, et al. A controlled trial of two nucleoside analogues plus indinavir in persons with human immunodeficiency virus and CD4 cell counts of 200 per cubic millimeter or less. N Engl F Med 1997;337: 725-33.

45 Carpenter CCJ, Fischl MA, Hammer SM, et al. Antiretroviral therapy for HIV infection in 1998: updated recommendations of the International AIDS Society-USA Panel. daMA 1998;280:78-86.

46 Rouzioux C, Costagliola D, Burgard M, et al and the HIV infection in newborns French Collaborative Study Group. Estimating timing of transmission of mother-to-child HIV-1 transmission by use of a Markov model. Am F Epidemiol 1995;142:1330-7.

47 Duliege AM, Amos CL Felton S, B et al. Birth order, delivery route, and concordance in the transmission of HIV-1 from mothers to twins. 7 Pediatr $1995 ; \mathbf{1 2 6}$ :625-32.

48 Mandelbrot L, Le Chenadec J, Berrebi A, et al. Perinatal HIV-1 transmission, interaction between zidovudine prophylaxis and mode of delivery in the French Perinatal prophylaxis and mode of delivery

49 Semprini AE. An international randomised trial of mode of delivery in HIV infected women. Abstracts of the 12th World AIDS Conference; 1998 June 28-July 3; Geneva, 1998 [Abstract 23599].

50 Read J. Mode of delivery and vertical transmission of HIV-1: a meta-analysis from fifteen prospective cohort studies (the International Perinatal HIV Group). Abstracts of the 12th World AIDS Conference; 1998 June 28-July 3; Geneva, 1998 [Abstract 23275].

51 de Jong MD, de Boer RJ, de Wolf F, et al. Overshoot of HIV-1 viraemia after early discontinuation of anti-retroviral treatment. AIDS 1997;11:F79-84.

52 Imrie A, Beveridge A, Genn W, V et al and the Sydney Primary HIV Infection Study Group. Transmission of human immunodeficiency virus type 1 resistant to nevirapine and zidovudine. F Infect Dis 1997;175:1502-6.

53 Hecht FM, Grant RM, Petropoulos CJ, et al. Sexual transmission of an HIV-1 variant resistant to multiple reverse-transcriptase and protease inhibitors. $N$ Engl F Med 1998;339:307-11.

54 Colgrove RC, Pitt J, Chung PH, et al. Selective vertical transmission of HIV-1 antiretroviral resistance mutations. AIDS 1998;12:2281-8.

55 Eastman PS, Shapiro DE, Coombs RW, et al. Maternal genotypic ZDV resistance and failure of ZDV to prevent mother-child HIV-1 transmission. Abstracts of the 4th Conference on Retroviruses and Opportunistic Infections 1997 January 22-26; Washington, DC, 1997:160 [Abstract 516]. 